Ciência Florestal, Santa Maria, v. 22, n. 3, p. 457-466, jul.-set., 2012

ISSN 0103-9954

\title{
ANÁLISE FITOSSOCIOLÓGICA DE UM FRAGMENTO DE FLORESTA ESTACIONAL EM UMA CATENA DE SOLOS NO MORRO DO CERRITO, SANTA MARIA, RS
}

\author{
PHYTOSOCIOLOGICAL ANALYSIS OF A FRAGMENT OF SEASONAL FOREST FOUND IN \\ THE SOIL CATENA ON MORRO DO CERRITO IN SANTA MARIA, RS, BRAZIL
}

\author{
Marcelo Callegari Scipioni ${ }^{1}$ Solon Jonas Longhi ${ }^{2}$ Catize Brandelero ${ }^{3}$ \\ Fabrício de Araújo Pedron ${ }^{4}$ Dalvan José Reinert ${ }^{5}$
}

\begin{abstract}
RESUMO
Este trabalho foi realizado em um fragmento da Floresta Estacional em estágio de sucessão secundária, na área do Morro do Cerrito, no Município de Santa Maria, RS, Brasil. O objetivo deste trabalho foi determinar os grupos florísticos presentes na área de estudo, quantificando a sociologia das principais espécies e sua relação com os compartimentos geomorfológicos e pedológicos. Para isso, foram alocadas unidades amostrais permanentes de $10 \mathrm{~m}^{2}$ distribuídas de forma contínua ao longo do gradiente topográfico do morro, iniciando na base e alcançando o cume. Foram medidos todos os indivíduos arbóreos com diâmetro altura do peito igual ou maior $5 \mathrm{~cm}$. Foi realizada análise de agrupamento pelo método hierárquico divisivo (TWINSPAN), tendo como variáveis o número de indivíduos das espécies e caracterizado os sítios dos grupos através de verificação no campo dos compartimentos geomorfológicos e análise morfológica e química dos solos. Foi constatada a presença de três grupos ecológicos ao longo do gradiente distribuídos de forma uniforme, que foram resultantes de diferentes condições sucessionais e ambientais proporcionados principalmente pelo substrato, classes de solos e posição na paisagem.
\end{abstract}

Palavras-chave: relação solo/planta; grupos ecológicos; ecologia florestal; pedologia.

\section{ABSTRACT}

This research took place in a semi-deciduous forest fragment in secondary succession stages on Morro do Cerrito in the municipality of Santa Maria, in the state of Rio Grande do Sul. The aim was to determine the floristic groups in the study area by quantifying the sociology of main species and their relationship with geomorphologic and pedological compartments. Permanent plots measuring $10 \mathrm{~m}^{2}$ were continuously allocated along the topographical gradient of the hill, beginning at the base and going to the top. All trees with diameter at breast equal or larger than $5 \mathrm{~cm}$ height were measured. Grouping analysis was performed by (Twinspan), having as variables the number of individuals of the species and characterized the sites of groups by testing in the field of geomorphological compartments and morphological and chemical analysis of soils. Three ecological groups were found evenly distributed along the gradient as a result of different successions and environmental conditions that were due mainly to the substrate, the soil classes, and landscape positions.

Keywords: soil-plant relationship; ecological groups; forest ecology; pedology.

1. Engenheiro Agrônomo e Florestal, MSc., Doutorando no Programa de Pós-Graduação em Engenharia Florestal, Centro de Ciências Florestais e da Madeira, Setor de Ciências Agrárias, Universidade Federal do Paraná, Funcionário do Serviço Florestal Brasileiro (Cenaflor), CEP 70818-900, Brasília (DF). marcelo.scipioni@gmail.com

2. Engenheiro Florestal, Dr., Professor do Departamento de Ciências Florestais, Centro de Ciências Rurais, Universidade Federal de Santa Maria, Campus Universitário, CEP 97105-900, Santa Maria (RS). sjlonghi@smail.ufsm.br

3. Engenheira Florestal, Dra., Professora do Departamento de Engenharia Rural, Centro de Ciências Rurais, Universidade Federal de Santa Maria, Campus Universitário, CEP 97105-900, Santa Maria (RS). catizebrandelero@yahoo.com.br

4. Engenheiro Agrônomo, Dr., Professor do Departamento de Solos, Centro de Ciências Rurais, Universidade Federal de Santa Maria, Campus Universitário, CEP 97105-900, Santa Maria (RS). fapedron@ufsm.br

5. Engenheiro Agrônomo, PhD., Professor do Departamento de Solos, Centro de Ciências Rurais, Universidade Federal de Santa Maria, Campus Universitário, CEP 97105-900, Santa Maria (RS). dalvan@ccr.ufsm.br

Recebido para publicação em 02/03/2010 e aceito em 20/06/2011

Ci. Fl., v. 22, n. 3, jul.-set., 2012 


\section{INTRODUÇÃO}

As florestas do estado do Rio Grande do Sul encontram-se profundamente alteradas. A devastação de grande parte das florestas foi causada por exploração intensiva de espécies madeireiras, a qual, aliada à substituição da floresta pelo avanço da fronteira agrícola, reduziu os maciços florestais, aumentando a fragmentação ou desaparecimento das mesmas, comprometendo a manutenção da diversidade biológica e a conservação dos recursos naturais (LONGHI et al., 1999; LONGHI et al., 2000; RAMBO, 2005; SCIPIONI et al., 2011a; KILCA e LONGHI, 2011).

A Floresta Estacional Decidual do Rio Grande do Sul, classificada assim, por Veloso et al. (1991) por causa da perda de mais de $50 \%$ das folhas das copas das árvores do dossel superior, é um desses grandes exemplos de descaracterização da vegetação natural, principalmente, pelo intenso corte seletivo de espécies caducifólias de valor madeireiro, que eram emergentes no dossel e responsáveis por essa fitofisionomia no período de inverno. A perda de grandes árvores, como as grápias (Apuleia leiocarpa), é evidente nessa tipologia florestal, que, segundo Leite e Klein (1990), a espécie é o principal elemento fisionômico decíduo na caracterização dessa formação florestal.

Essa mudança causada pelo homem é confirmada pelo levantamento fenológico realizado por Alberti et al. (2011) em um fragmento de Floresta Estacional Decidual no Morro do Cerrito, onde avaliaram quantitativamente a fenologia florestal, e constataram um valor máximo de $43 \%$ das copas do dossel superior com perda das folhas no inverno. Portanto, a decidualidade foi menor que $50 \%$, confirmando a eliminação das árvores caducifólias do dossel superior, e consequentemente, a mudança na fisionomia e composição florística desse remanescente.

A variação na biodiversidade e estrutura das florestas é um processo dinâmico constante, às vezes lento e natural, podendo também ser ríspido quando há intervenção do homem sem manejo adequado ou de um fenômeno ambiental extremo. O efeito, a escala e a frequência desses distúrbios são diversos, como também, as suas proporções e resultados, às vezes são percebidas imediatamente ou somente depois de algum tempo, por meio da sucessão que pode ser ordenada e previsível ou opostamente imprevisível. Contudo, os ecólogos têm acumulado uma grande quantidade de informações sobre processos sucessionais. Em vez de uma única teoria unificada, o que se tem é um conjunto complexo de processos interconectados, que constituem uma estrutura de interações entre os indivíduos e o meio abiótico (COLLINS et al., 1993; GUREVITCH et al., 2009).

Atualmente, existem muitos dados fitossociológicos nas vertentes da Floresta Estacional Decidual (LONGHI et al., 1986; MACHADO e LONGHI, 1990; LONGHI et al., 1999; LONGHI et al., 2000, SCIPIONI et al., 2011b). Por outro lado, são poucos os estudos realizados para conhecer a sociologia dessas florestas integradas com relações abióticas, visando maiores detalhes em relação ao substrato, principalmente com análises locais dos solos e do relevo. Pode-se citar os trabalhos realizados por Vacarro et al. (1999) que analisam as categorias sucessionais no município de Santa Teresa, RS, e Scipioni et al. (2010), na Reserva Biológica do Ibicuí-Mirim, no município de São Martinho da Serra, RS.

O conhecimento de solo e relevo são fatores importantes para avaliar grupos florísticos em situações locais, sendo que o clima nessas situações é uma variável homogênea e não interfere fortemente sobre a mudança da vegetação. Mas, o relevo e a posição na paisagem influenciam na incidência da radiação luminosa sobre as plantas e, também, na pedogênese, possibilitando a existência de diferentes classes de solos com distintas condições físicas, químicas, hídricas e biológicas. Fatores esses, que influem de forma conjunta na distribuição das espécies arbóreas e na formação de diferentes comunidades na floresta (PUIG, 2008; GUREVITCH et al., 2009).

Os morros testemunhos do Rebordo da Serra Geral são gradientes complexos pela formação geológica e geomorfológica e, consequentemente, possibilitam uma variação de solos que refletem as condições ambientais dos sítios florestais com diversas espécies, onde as suas relações ainda são pouco conhecidas (SCIPIONI et al., 2010).

Assim, a existência de grande quantidade de espécies e variáveis ambientais é um desafio para as análises dessas comunidades vegetais, que, somente com o advento de procedimentos estatísticos multivariados voltados para análise da vegetação, tornou possível a verificação de relações complexas com o meio ambiente. As técnicas multivariadas, classificação e ordenação, permitem analisar e correlacionar grande quantidade de espécies com variáveis ambientais de uma floresta, possibilitando, 
assim, o melhor entendimento das relações ecológicas por meio das variáveis respostas pela redução do grande número de variáveis observadas, com a mínima perda de informação (JONGMAN et al., 1995; FELFILI et al., 2007; GUREVITCH et al., 2009).

O Morro do Cerrito, objeto deste estudo, está numa situação ambiental complexa, que necessita de maior detalhamento. O local encontra-se numa área de pressão antrópica, por ser um fragmento florestal urbano de domínio particular sobre uma área de intensa especulação imobiliária, sendo necessário o melhor conhecimento das relações fitossociológica das espécies arbóreas no gradiente geopedológico desse local, antes que as atividades antrópicas descaracterizem o que resta dessa vegetação.

Neste contexto, o presente trabalho tem o objetivo de determinar os grupos ecológicos presentes na área de estudo, quantificando a sociologia das principais espécies arbóreas de cada grupo e relacionando-os com os compartimentos geomorfológicos e pedológicos dos sítios de ocorrência no gradiente topográfico. De forma que, o melhor conhecimento do comportamento ecológico e sucessional da comunidade e das principais espécies arbóreas, possam também fornecer subsídios para aplicação de planos de recuperação e restauração de áreas de semelhança ambiental, especialmente nos morros situados entre a região da Depressão Central e o Rebordo da Serra Geral no estado do Rio Grande do Sul.

\section{MATERIAL E MÉTODO}

\section{Descrição da área de estudo}

Este trabalho foi realizado no Morro do Cerrito, na cidade de Santa Maria, situada entre os paralelos $29^{\circ} 43^{\prime}$ e $29^{\circ} 44^{\prime}$ de latitude Sul e $53^{\circ} 42^{\prime}$ e $53^{\circ} 44^{\prime}$ de longitude Oeste de Greenwich, na região central do estado do Rio Grande do Sul, Brasil. A Figura 1 mostra um modelo tridimensional da área de estudo elaborado com subsídio da carta topográfica da área na escala de 1:25.000 (BRASIL, 1992) com equidistância vertical das curvas de nível de $10 \mathrm{~m}$. As cotas altimétricas na área de estudo apresentaram variação entre 160 a $246 \mathrm{~m}$. O fragmento contém aproximadamente 20 ha e vem apresentando intervenção humana há cerca de 90 anos com cortes seletivos, estando atualmente em estado de sucessão secundária avançada.

$\mathrm{O}$ clima da região pertence ao tipo $\mathrm{Cfa}$, subtropical úmido sem estiagem, conforme a classificação climática de Köppen. A temperatura média anual oscila em torno de $19,2{ }^{\circ} \mathrm{C}$, com a temperatura média do mês mais frio de $13,8^{\circ} \mathrm{C}$, enquanto a precipitação média anual é de $1708 \mathrm{~mm}$, sendo bem distribuída ao longo do ano (MALUF, 2000).

O Morro do Cerrito encontra-se na área de transição da região do Planalto Médio Gaúcho para a Depressão Central do estado, sendo considerado um morro testemunho da regressão do Planalto vulcânico da Serra Geral. Na área de estudo, o relevo apresenta-se com variação de escarpado (declividade superior a $75 \%$ ) a suave ondulado (declividade entre 3 e $8 \%$ ). Os materiais geológicos predominantes são dos tipos vulcânicos básicos (basaltos e diabásios) pertencentes à Formação Serra Geral, e sedimentares pertencentes à Formação Caturrita (MACIEL FILHO, 1990). A formação Caturrita, topo da sequência Triássica, é constituída por arenitos depositados por sistemas fluviais de canais isolados a meandrantes, com litofácies pelíticas associadas à tendência de topo da unidade.

\section{Amostragem e processamento de dados}

A coleta de dados foi realizada em unidades amostrais permanentes de $10 \times 10 \mathrm{~m}\left(100 \mathrm{~m}^{2}\right)$, distribuídas de forma contínua sobre uma linha amostral, prolongando-se sobre o gradiente geomorfológico (Figura 1). Em cada unidade amostral foram identificadas e medidas as espécies arbóreas de diâmetros altura do peito maior ou igual a $5 \mathrm{~cm}$, sendo numeradas e marcadas com placas de alumínio.

Para obtenção dos grupos ecológicos foi utilizada a análise de agrupamento pelo método hierárquico divisivo (TWINSPAN - Two-Way INdicato SPecies ANalysis) descrito por Jongman et al. (1995) e Felfili et al. (2007), utilizando o programa computacional PC-ORD for Windows versão 5.0 (MCCUNE e MEFFORD, 2006), com a matriz de densidade de indivíduos de 60 espécies em 53 parcelas. Além da análise estatística, a definição dos grupos baseou-se na composição florística das parcelas associando fatores ecológicos e ambientais, sendo que as divisões dos grupos foram de acordo com o autovalor $\geq 0,30$, considerando somente as divisões que puderam ser explicadas e apresentaram importância ecológica (FELFILI et al., 2007; RIBEIRO et al., 2007).

Após a obtenção das espécies indicadoras e dos grupos ecológicos pela análise do TWINSPAN, foi desenvolvido um gráfico com a densidade das 
principais espécies indicadoras para visualizar a distribuição das mesmas ao longo do gradiente e na delimitação dos grupos ecológicos. Para representar a fitossociologia do componente arbóreo da amostra total e dos grupos, foram consideradas somente as espécies de maior valor de importância, pelos parâmetros de Muller-Dombois e Ellenberg (1974), considerando somente as espécies que representaram aproximadamente $50 \%$ do valor importância (VI) acumulado em ordem decrescente.

Os dados sobre a cobertura geológica foram obtidos no trabalho de Maciel Filho (1990) e através de conferência no campo. Os dados sobre a cobertura pedológica foram obtidos em levantamento detalhado dos solos nas parcelas amostradas. Os diferentes solos existentes na área de trabalho foram identificados e amostrados conforme procedimentos de Santos et al. (2005) e classificados segundo o Sistema Brasileiro de Classificação de Solos (EMBRAPA, 2006). Amostras dos perfis de solos, em cada horizonte, foram coletadas para análise química de rotina e análise granulométrica pelo método da pipeta, conforme procedimentos propostos pela Embrapa (1997).
Os dados foram processados no programa Mata Nativa 2.0 (CIENTEC, 2006), com o qual foram obtidos os valores de densidade, frequência e dominância absolutas e relativas, e os valores de importância das principais espécies presentes nos grupos ecológicos.

\section{RESULTADOS E DISCUSSÃO}

\section{Caracterização ambiental}

Os trabalhos de campo permitiram a identificação de cinco compartimentos geomorfológicos que apresentam sequência de solos diferentes (Tabela 1). Foi verificado o mesmo material de origem para os quatro compartimentos mais altos, derivados do arenito da Formação Caturrita, enquanto o compartimento inferior é formado por sedimentos arenosos erodidos das áreas mais altas.

A distribuição dos solos apresentou relação direta com a geomorfologia da área, onde a porção mais alta e declivosa do morro foram classificadas como encosta superior, constituída por solos rasos com alta pedregosidade do tipo Neossolos Litólicos, Neossolos Regolíticos e Cambissolos Háplicos. Os

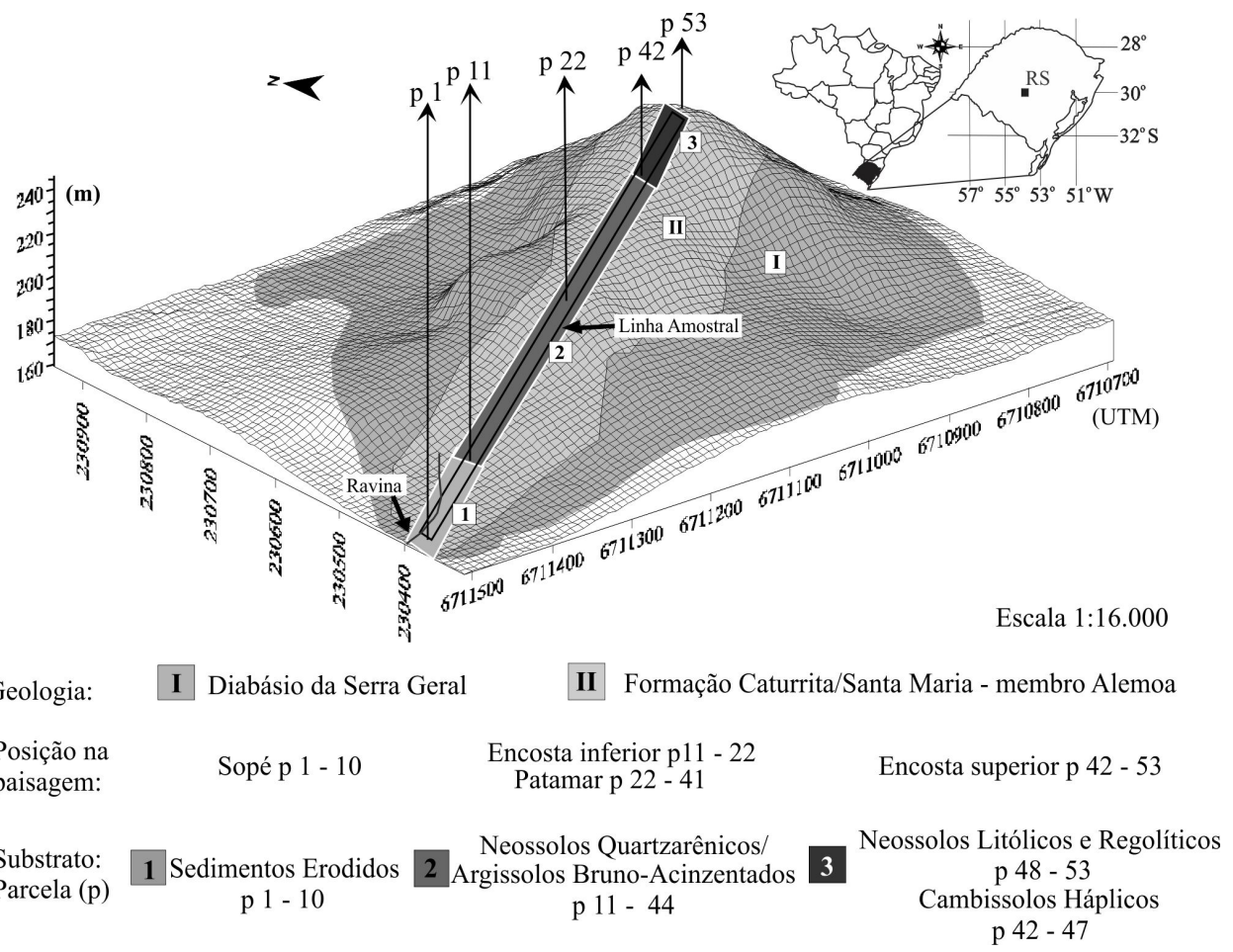

FIGURA 1: Área de estudo com indicação do gradiente geomorfológico, altitudes e coordenadas geográficas, e as classes de solos encontradas nas parcelas (p) no Morro do Cerrito, Santa Maria, RS.

FIGURE 1: Study area indicating geomorphologic gradient, altitudes and geographic coordinates, and soil classes found on the plots (p) in Morro do Cerrito, Santa Maria, RS. 
TABELA 1: Caracterização ambiental, morfológica e química dos solos encontrados no Morro do Cerrito, RS.

TABLE 1: Environmental characterization, morphology and soil chemistry found in Morro do Cerrito, RS.

\begin{tabular}{|c|c|c|c|c|c|c|c|c|}
\hline Solo & $\begin{array}{c}\text { Posição na } \\
\text { paisagem }\end{array}$ & Relevo $^{1}$ & $\mathrm{CP}^{2}$ & $\begin{array}{c}\text { Profundidade } \\
\text { efetiva }\end{array}$ & Drenagem $^{3}$ & $\mathrm{CTC}^{4}$ & $\mathrm{~V}^{5}$ & $\begin{array}{l}\text { Argila } \\
\left(\mathrm{g} \mathrm{kg}^{-1}\right)\end{array}$ \\
\hline $\begin{array}{c}\text { Neossolo } \\
\text { Regolítico e } \\
\text { Neossolo Litólico }\end{array}$ & $\begin{array}{l}\text { Encosta } \\
\text { superior }\end{array}$ & E & MP & $60 \mathrm{~cm}$ & $\mathrm{BD}$ & 33,6 & 23 & 156 \\
\hline $\begin{array}{l}\text { Cambissolo } \\
\text { Háplico }\end{array}$ & $\begin{array}{l}\text { Encosta } \\
\text { Superior }\end{array}$ & M & $\mathrm{P}$ & $70 \mathrm{~cm}+$ & $\mathrm{BD}$ & 30,2 & 50 & 130 \\
\hline $\begin{array}{l}\text { Argissolo Bruno- } \\
\text { Acinzentado }\end{array}$ & Patamar & $\mathrm{SO}$ & NP & $100 \mathrm{~cm}+$ & ID & $\begin{array}{l}17,8 / \\
48,5\end{array}$ & $43 / 22$ & $116 / 293$ \\
\hline $\begin{array}{c}\text { Neossolo } \\
\text { Quartzarênico }\end{array}$ & Patamar & SO & $\mathrm{NP}$ & $150 \mathrm{~cm}$ & BD a ID & 5,2 & 43 & 47 \\
\hline $\begin{array}{l}\text { Argissolo Bruno- } \\
\text { Acinzentado }\end{array}$ & $\begin{array}{l}\text { Encosta } \\
\text { inferior }\end{array}$ & $\mathrm{O}$ & NP & $100 \mathrm{~cm}+$ & ID a MD & $\begin{array}{l}14,3 / \\
25,0\end{array}$ & $46 / 44$ & $99 / 212$ \\
\hline $\begin{array}{l}\text { Sedimentos } \\
\text { erodidos }\end{array}$ & Sopé & SO & NP & $80 \mathrm{~cm}+$ & ID a MD & 7,7 & 21 & 63 \\
\hline
\end{tabular}

Em que: ${ }^{~}$. Relevo: $\mathrm{E}=$ escarpado; $\mathrm{M}=$ montanhoso; $\mathrm{O}=$ ondulado; $\mathrm{SO}=$ Suave ondulado a ondulado. ${ }^{2}$ Classes de pedregosidade $(\mathrm{CP})$ : $\mathrm{MP}=$ muito pedregoso; $\mathrm{P}=$ pedregoso; $\mathrm{NP}=$ não pedregoso. ${ }^{3}$ Classes de drenagem: $\mathrm{BD}=$ bem drenado; ID = imperfeitamente drenado; $\mathrm{MD}=$ mal drenado. ${ }^{4} \mathrm{CTC}$ : Capacidade de Troca Catiônica $\left(\mathrm{cmol}_{\mathrm{c}} \mathrm{kg}^{-1}\right)$. Valores individuais referem-se ao horizonte superficial A, valores separados por barra referem-se ao horizonte superficial A e subsuperficial B. ${ }^{5}$ V: saturação por bases (\%).

patamares, com relevo de suave ondulado a ondulado são constituídos por solos mais desenvolvidos e profundos, com Argissolos Bruno-Acinzentados associados aos Neossolos Quartzarênicos. A encosta inferior, com relevo ondulado, é constituída, predominantemente, por Argissolos BrunoAcinzentados. Enquanto o sopé, com relevo de suave ondulado a ondulado, é constituído por sedimentos erodidos.

A encosta superior difere-se dos demais compartimentos também pela presença de solos bem drenados e com CTC mais elevada. Os demais compartimentos apresentam solos mais profundos, drenagem imperfeita, ausência de pedregosidade em superfície e CTC relativamente inferior. Em relação à saturação por bases, praticamente toda a área de estudo apresenta solos distróficos, com relativa acidez no complexo de troca catiônica. Os teores de argila são considerados baixos, caracterizando solos arenosos, com baixa disponibilidade de nutrientes, e alta suscetibilidade à erosão (PEDRON et al., 2006).

\section{Análise de Agrupamento}

No gradiente topográfico do Morro do Cerrito foi constatada, de forma ordenada, a distribuição espacial das unidades amostrais pela análise de agrupamento, podendo separar quatro grupos florísticos (Figura 2). Na primeira divisão (autovalor igual a 0,4257), entre os grupos 1 e 2, as espécies indicadoras foram Trichilia claussenii (grupo 1) e Cupania vernalis (grupo 2).

Scipioni et al. (2011b) analisando a fitossociologia e as subformações de um fragmento de Floresta Estacional Decidual no noroeste do estado do Rio Grande do Sul, constataram as mesmas espécies indicadoras no primeiro nível de divisão e consideraram essas espécies como responsáveis pela identificação dos estágios secundários avançado e inicial para as respectivas espécies, Trichilia claussenii e Cupania vernalis, resultado semelhante ao encontrado nesse estudo.

Essas espécies ocorreram com frequência e abundância no estrato médio e inferior da floresta do estudo, sendo esse o comportamento comum na Floresta Estacional Decidual conforme diversos estudos fitossociológicos realizados até o momento (LONGHI et al., 1986; MACHADO e LONGHI, 1990; MACHADO e LONGHI, 1991; LONGHI et al., 1999; LONGHI et al., 2000; SCIPIONI et al., 2011a, SCIPIONI et al., 2011b). 
Segundo Scipioni et al. (2011b), essas espécies são responsáveis pela distinção dos estágios florestais secundários e da fisionomia do interior da floresta, por apresentar alta densidade e frequência. De forma que, as altas densidades destas espécies determinam que as mesmas sejam indicadoras e formadoras de grupos ecológicos pela análise estatística, e também, podem caracterizar a fisionomia interna da floresta.

Nos trabalhos de Longhi et al. (1986) e Scipioni et al. (2011a), os autores consideraram a espécie, Trichilia claussenii, como característica do estágio secundário avançado da floresta, por essa ser abundante e dominante nos estratos inferior e médio da floresta em dossel fechado e apresentar uma floresta mais conservada, enquanto Vaccaro et al. (1999), a consideraram do sub-bosque devido à espécie desenvolver-se em baixo do dossel da floresta madura. Assim, pode-se considerar a espécie como uma planta esciófita, que segundo Lorenzi (2000) é característica do interior da floresta primária.

Em estudo fitossociológico correlacionando solos e relevo no interior da Serra Geral foi constatado a presença da espécie Trichilia claussenii em todos os compartimentos da topossequência sobre Neossolos Litólicos bem drenados (SCIPIONI et al., 2011a). Esse resultado foi semelhante ao estudo de Longhi et al. (1986) no município de Candelária (RS) sobre o morro Botucaraí, onde a espécie também foi a mais abundante nos três compartimentos ao longo da catena da área amostrada, que abrangeu a encosta inferior e superior e o topo do morro. Embora esses autores não tenham identificado os solos do local, as condições ambientais sugerem se tratar dos mesmos Neossolos Litólicos.

No Morro do Cerrito, os resultados

\section{Amostra total \\ $\mathrm{N}=53$ parcelas \\ Espécies $=60$ \\ Divisão 1 Autovalor $=0,4257$}

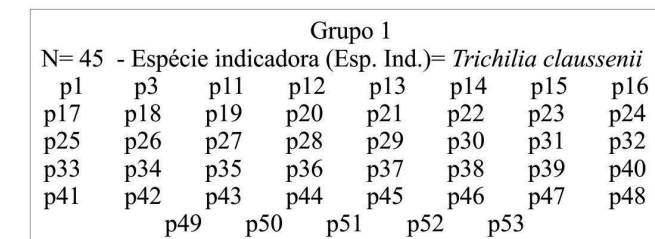

Divisão 2 Autovalor $=0,4196$

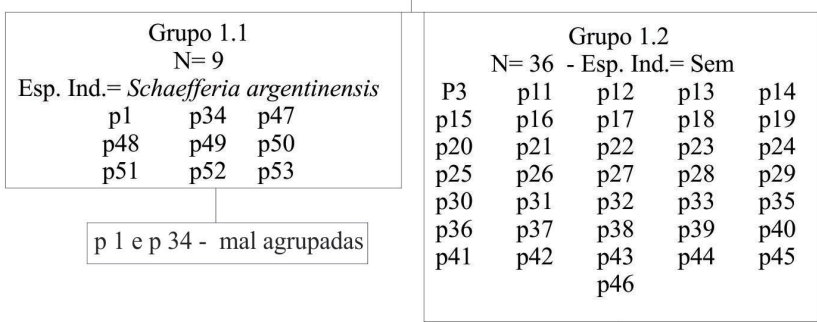

\begin{tabular}{|c|c|}
\hline 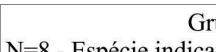 & po 2 \\
\hline $\mathrm{N}=\gamma-$ Especie indica & ania vernalis \\
\hline p4 & p6 \\
\hline $\mathrm{p} 7$ & p10 \\
\hline Divisão 3 & Autovalor $=0,5480$ \\
\hline Grupo 2.1 & Grupo 2.2 \\
\hline $\begin{array}{c}N=4 \\
\text { Esp. Ind.= }\end{array}$ & $\begin{array}{c}\mathrm{N}=4 \\
\text { Esp. Ind. }=\end{array}$ \\
\hline Schefflera & Cabralea canjera, \\
\hline morototoni & Enterolobium \\
\hline $\begin{array}{l}\text { e Chrysophyllum } \\
\text { gonocarpum }\end{array}$ & $\begin{array}{l}\text { contortisiliquum } \\
\text { e Cordia americana }\end{array}$ \\
\hline p8 & $\mathrm{p} 4$ \\
\hline p10 & p6 \\
\hline
\end{tabular}

p 11 e p 45 - parcelas de borda

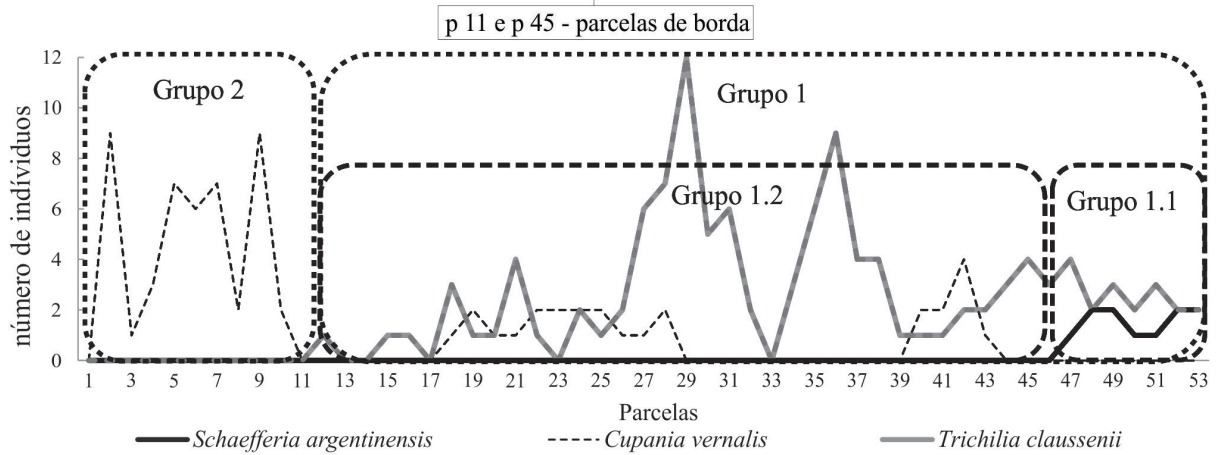

FIGURA 2: Dendrograma da classificação dos grupos ecológicos e a densidade por parcela das principais espécies indicadoras na determinação dos grupos ecológicos no Morro do Cerrito, Santa Maria, RS.

FIGURE 2: Dendrogram of classification of ecological groups and density plot of the main indicator species for the determination of ecological groups in Morro do Cerrito, Santa Maria, RS. 
foram semelhantes aos demais estudos citados anteriormente, com exceção do sopé do morro. Local com aspecto determinante da diferença desses dois grandes grupos ( 1 e 2), onde a situação ambiental encontrada nas parcelas 1 a 10 , situadas no sopé da catena, sendo caracterizadas pela deposição de sedimentos arenosos erodidos das áreas mais altas, apresentando drenagem imperfeita, podendo ocorrer pequenas porções com Argissolos Bruno-Acinzentados e Argissolos Amarelos. Em parte desta área foi constatado um processo erosivo, devido às convergências hídricas provindas das cotas superiores do morro, formando uma ravina. Como a ravina ocupa boa parte das parcelas 1 a 10 , houve um menor estabelecimento de espécies arbóreas, consequentemente, a floresta apresenta um dossel com maior abertura que permite maior entrada de luz, além de apresentar uma borda florestal mais estreita do fragmento em comparação ao local que se encontra o grupo 2 no gradiente. Por isso, a espécie Trichilia claussenii não se estabeleceu nesse ambiente, caracterizando uma situação abrupta na separação dos grupos ecológicos 1 e 2, em floresta com estágio secundário inicial (Grupo 1) e avançado (Grupo 2), facilmente visualizado na separação desses grupos no dendrograma e no gráfico de densidade dessas espécies ao longo do gradiente ambiental na Figura 2.

Desta forma, a espécie Cupania vernalis apresentou maior densidade e foi favorecida por apresentar um comportamento ecológico mais tolerante à luz do que a Trichilia claussenii, sendo que a espécie também é citada ocorrendo esporadicamente em áreas abertas (LORENZI, 2000; SANTANDER e GONZÁLEZ, 2007).

$\mathrm{Na}$ classificação pelo método de TWINSPAN, os dois grandes grupos 1 e 2, dividiram-se em mais dois grupos cada, sendo a divisão 2 com autovalor de 0,4196 (grupos $1.1 \mathrm{e}$ 1.2) e a divisão 3 com autovalor de 0,5480 (grupos 2.1 e 2.2), conforme Figura 2.

No grupo 1, ocorreu a formação de um pequeno grupo (1.1) com 7 unidades amostrais que estavam situadas no cume do cerro e apresentou a espécie Schaefferia argentinesis como indicadora desse ambiente (Figura 2). Em termos ambientais, as parcelas que constituem o grupo 1.1 encontram-se no compartimento de encosta superior, caracterizado por apresentar declividade alta, pedregosidade em superficie e presença de solos rasos e bem drenados, como os Neossolos Litólicos, Neossolos Regolíticos e Cambissolos Háplicos. Além disso, a elevada declividade e posição na paisagem deste compartimento confere maior luminosidade, tornando-o distinto dos demais compartimentos do estudo.

O grupo 1.2 não apresentou espécie indicadora, mas pela posição hierárquica em relação ao grupo 1, pode-se considerar a Trichilia claussenii como tal. Espacialmente, o grupo 1.2 que apresentou a maior área de abrangência espacial $(\mathrm{N}=36)$, na porção intermediária da topossequência, entre os grupos ecológicos 1.1 e 2 (Figura 2). O grupo 1.2 caracteriza-se por ocorrer em área menos declivosa, com ausência de pedregosidade, e solos com profunfidade efetiva superior a $100 \mathrm{~cm}$ e drenagem imperfeita, como predomínio de Argissolos Bruno-Acinzentados e Neossolos Quartzarênicos.

Conforme a análise de TWINSPAN as parcelas 11 e 45 foram consideradas como limite entre grupos (bordelines). Segundo Felfili et al. (2007), bordelines são aquelas parcelas que não apresentam diferença significativa para serem classificadas em um dos grupos. Neste caso, essas duas parcelas foram enquadradas no grupo 1.2, por apresentarem maior semelhança florística e ambiental em relação aos grupos vizinhos.

Na Tabela 2 são apresentadas as espécies de maior importância com os parâmetros fitossociológicos, na amostragem total e por grupo ecológico, que representavam aproximadamente $50 \%$ do valor de importância (VI) acumulado. Ficou evidente a importância fitossociológica das espécies indicadoras na análise de agrupamento, além de outras espécies que também auxiliam na caracterização ecológica e florística dos grupos. Como foi verificado no grupo 1.1, a dominância da espécie Helietta apiculata (canela-de-veado), que ocorre comumente sobre solos litólicos nos cumes dos morros testemunhos na Depressão Central do Rio Grande do Sul, como exemplo, o Morro Cechela na cidade de Santa Maria.

Em relação às espécies que contribuíram com os 50 \% aproximados do valor de importância, na área degradada da ravina (grupo 2), o número de espécies contribuintes foi menor, apenas quatro espécies em comparação com os outros dois grupos que foram sete espécies em cada, consequentemente, fez com que a contribuição da principal espécie indicadora no valor de importância do grupo 2, Cupania vernalis, seja muito maior do que o valor individual das demais espécies indicadoras de maior VI nos demais grupos (Tabela 2). Isso possibilita 
TABELA 2: Parâmetros fitossociológicos total e dos principais grupos ecológicos, com a descrição dos valores das espécies de maior importância responsáveis pelo acúmulo aproximado de 50 \% VI.

TABLE 2: Phytosociological parameters of the main ecological groups and their totals, with descriptions of the value of the more important species responsible for accumulating approximately $50 \%$ of the Importance Value (IV).

\begin{tabular}{|c|c|c|c|c|c|c|c|c|}
\hline Grupos & Espécies & $\mathrm{N}$ & ind./ha & FA (\%) & FR (\%) & $\mathrm{m}^{2 / h a}$ & VI & VI (\%) \\
\hline \multirow{9}{*}{$\begin{array}{c}\text { Geral } \\
\text { VI acumulado } \\
49,96 \%\end{array}$} & Trichilia claussenii & 117 & 221 & 69,81 & 8,39 & 3,09 & 29,64 & 9,88 \\
\hline & Gymnanthes concolor & 152 & 287 & 52,83 & 6,35 & 1,32 & 27,55 & 9,18 \\
\hline & Cupania vernalis & 72 & 136 & 45,28 & 5,44 & 2,08 & 18,94 & 6,31 \\
\hline & Myrcianthes pungens & 53 & 100 & 52,83 & 6,35 & 2,42 & 18,39 & 6,13 \\
\hline & Chrysophyllum marginatum & 26 & 49 & 37,74 & 4,54 & 2,36 & 13,24 & 4,41 \\
\hline & Sorocea bonplandii & 43 & 81 & 41,51 & 4,99 & 0,50 & 11,28 & 3,76 \\
\hline & Ficus cestrifolia & 3 & 6 & 5,66 & 0,68 & 4,25 & 11,16 & 3,72 \\
\hline & Chrysophyllum gonocarpum & 30 & 57 & 32,08 & 3,85 & 1,54 & 11,07 & 3,69 \\
\hline & Cordia americana & 17 & 32 & 22,64 & 2,72 & 1,63 & 8,63 & 2,88 \\
\hline & Total Geral & 842 & 1589 & 832,08 & 100 & 42,02 & 300 & 100 \\
\hline \multirow{8}{*}{$\begin{array}{c}\text { Grupo } 1.1 \\
\text { VI acumulado } \\
49,47 \% \\
\text { (encosta } \\
\text { superior) }\end{array}$} & Ficus cestrifolia & 1 & 14 & 14,29 & 1,20 & 16,42 & 27,44 & 9,15 \\
\hline & Helietta apiculata & 14 & 200 & 85,71 & 7,23 & 5,54 & 26,05 & 8,68 \\
\hline & Trichilia claussenii & 18 & 257 & 100,00 & 8,43 & 1,97 & 24,63 & 8,21 \\
\hline & Myrcianthes pungens & 13 & 186 & 71,43 & 6,02 & 4,43 & 22,39 & 7,46 \\
\hline & Schaefferia argentinensis ${ }^{1}$ & 11 & 157 & 100,00 & 8,43 & 1,54 & 18,85 & 6,28 \\
\hline & Cordia americana & 5 & 71 & 42,86 & 3,61 & 5,20 & 15,34 & 5,11 \\
\hline & Ficus luschnathiana & 3 & 43 & 42,86 & 3,61 & 5,11 & 13,75 & 4,58 \\
\hline & Total do Grupo 1.1 & 137 & 1957 & 1185,71 & 100 & 64,37 & 300 & 100 \\
\hline \multirow{8}{*}{$\begin{array}{c}\text { Grupo } 1.2 \\
\text { VI acumulado } \\
50,03 \% \\
\text { (patamar } \\
\text { e encosta } \\
\text { inferior) }\end{array}$} & Gymnanthes concolor & 150 & 417 & 72,22 & 8,61 & 1,93 & 38,33 & 12,78 \\
\hline & 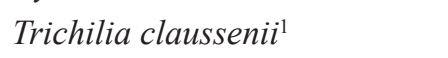 & 99 & 275 & 83,33 & 9,93 & 4,16 & 36,49 & 12,16 \\
\hline & Myrcianthes pungens & 40 & 111 & 63,89 & 7,62 & 2,70 & 20,78 & 6,93 \\
\hline & Chrysophyllum marginatum & 22 & 61 & 47,22 & 5,63 & 2,98 & 16,47 & 5,49 \\
\hline & Sorocea bonplandii & 41 & 114 & 55,56 & 6,62 & 0,71 & 15,18 & 5,06 \\
\hline & Cupania vernalis & 26 & 72 & 41,67 & 4,97 & 1,32 & 12,49 & 4,16 \\
\hline & Chrysophyllum gonocarpum & 18 & 50 & 30,56 & 3,64 & 1,54 & 10,34 & 3,45 \\
\hline & Total do Grupo 1.2 & 598 & 1661 & 838,8 & 100 & 41,64 & 300 & 100 \\
\hline \multirow{5}{*}{$\begin{array}{c}\text { Grupo } 2 \\
\text { VI acumulado } \\
53,41 \% \\
\text { (sopé) } \\
\end{array}$} & Cupania vernalis $^{1}$ & 45 & 563 & 100,00 & 17,78 & 7,59 & 91,58 & 30,53 \\
\hline & Chrysophyllum gonocarpum & 10 & 125 & 50,00 & 8,89 & 2,57 & 28,38 & 9,46 \\
\hline & Enterolobium contortisiliquum & 3 & 38 & 37,50 & 6,67 & 4,37 & 25,03 & 8,34 \\
\hline & Parapiptadenia rigida & 2 & 25 & 25,00 & 4,44 & 2,50 & 15,25 & 5,08 \\
\hline & Total do Grupo 2 & 95 & 1188 & 562,5 & 100 & 28,72 & 300 & 100 \\
\hline
\end{tabular}

Em que: ${ }^{1}=$ Espécie indicadora.

concluir, que nessa área perturbada existe maior dominância da espécie indicadora, pois tem menor competição desta com as demais espécies e devido a essa ter maior adaptabilidade nesse ambiente de maior luminosidade no interior da floresta que restringe o desenvolvimento de espécies esciófilas, como as espécies indicadoras: Trichilia clausenii, Sorocea bonplandii, Myrcianthes pungens e Gymnanthes concolor, por conseguinte, menor diversidade de espécies no interior da floresta.

\section{CONCLUSÕES}

No gradiente topográfico do Morro do Cerrito foi constatado três grupos florísticos com relações ecológicas e ambientais distintas.

O primeiro grupo (1.1), com Schaefferia argentinesis como espécie indicadora, relacionouse com as áreas mais declivosas e altas da encosta superior, onde ocorrem solos rasos, pedregosos e bem drenados do tipo Neossolos Litólicos, 
Neossolos Regolíticos e Cambissolos Háplicos.

O segundo grupo (1.2), sem espécie indicadora, mas com predominância de Trichilia claussenii, relacionou-se com os patamares e a encosta inferior, onde ocorrem solos imperfeitamente drenados, arenosos e profundos do tipo Neossolos Quartzarênicos e Argissolos Bruno-Acinzentados, que caracteriza a floresta em estágio secundário avançado de sucessão.

O terceiro grupo (2), com dominância de Cupania vernalis, apresentou forte relação com as condições ambientais do sopé, caracterizadas pela deposição de sedimentos erodidos, pelo ravinamento e concentração dos fluxos hídricos das áreas mais baixa, proporcionando menor densidade de espécies arbóreas e maior abertura de dossel e, consequentemente, maior incidência de luz no interior do fragmento florestal, que caracteriza a floresta em estágio secundário inicial avançado de sucessão.

\section{REFERÊNCIAS BIBLIOGRÁFICAS}

ALBERTI, L.F. et al. Padrão fenológico de árvores e a relação com o clima em floresta estacional no Sul do Brasil. In: SCHUMMACHER et al. (Orgs.). Floresta Estacional Subtropical: Caracterização e Ecologia nas Escarpas da Serra Geral. Santa Maria: UFSM, 2011. cap. 6, p.105-119.

BRASIL. Folha SH.22-V-C-IV/1-SE, Santa Maria-SE. Brasília: Ministério do Exército, Departamento de Engenharia e Comunicações: Diretoria de Serviço Geográfico. Região Sul do Brasil, 1992. Escala 1:25.000.

CIENTEC. Software Mata Nativa 2: Sistema para análise fitossociológica, elaboração de inventários e planos de manejo de florestas nativas. Viçosa: Cientec, 2006.

COLLINS, S. L. et al. The hierarchical continuum concept. Journal of Vegetation Science, Washington, n. 4, p. 149-156, 1993.

EMBRAPA. Empresa Brasileira de Pesquisa Agropecuária, Centro Nacional de Pesquisa de Solos. Manual de métodos de análises de solo. 2. ed. Rio de Janeiro: EMBRAPA, 1997. 212 p.

EMBRAPA. Empresa Brasileira de Pesquisa Agropecuária, Centro Nacional de Pesquisa de Solos. Sistema de Classificação Brasileiro de Classificação de Solos. 2. ed. Rio de Janeiro: EMBRAPA, 2006. 306 p.

FELFILI, J. M. et al. Análise multivariada em estudos de vegetação. Brasília: Universidade de
Brasília, Departamento de Eng. Florestal, 2007. 60

p. (Comunicações Técnicas Florestais, v.9, n.1).

GUREVITHCH, J. et al. Ecologia Vegetal. 2 ed. Porto Alegre: Artmed, 2009. 592 p.

JONGMAN, R. H. G. et al. Data analysis in community and landscape ecology. 2nd ed. Cambrigde: Cambrigde University Press, 1995. 299 p.

KILCA, R.; LONGHI, S. J. A composição florística e a estrutura das florestas subtropicais estacionais nas escarpas do Planalto Meridional do Rio Grande do Sul In: SCHUMACHER et al. (Orgs.). Floresta Estacional Subtropical: Caracterização e Ecologia nas Escarpas da Serra Geral. Santa Maria: UFSM, 2011. cap. 4, p. 53-83.

LEITE, P. F.; KLEIN, R. M. Vegetação. In: Fundação Instituto Brasileiro de Geografia e Estatística. Geografia do Brasil: região sul. Rio de Janeiro: IBGE, 1990. p. 113 - 150.

LONGHI, S. J. et al., Aspecto fitossociológico de fragmento de Floresta Estacional Decidual, Santa Maria, RS. Ciência Florestal, Santa Maria, v. 10, n. 2, p. 59-74, 2000.

LONGHI, S. J. et al., Diferenciação dos tipos florestais do morro Botucaraí, em Candelária, Rio Grande do Sul. Acta For. Bras., Curitiba, n. 1, p. 99-114, 1986.

LONGHI, S. J. et al, Composição florística e estrutura da comunidade arbórea de um fragmento florestal no município de Santa Maria, Brasil. Ciência Florestal, Santa Maria, v. 9, n. 1, p. 115133, 1999.

LORENZI, H. Árvores brasileiras: manual de identificação e cultivo de plantas arbóreas nativas do Brasil. vol.1, 3. ed. Nova Odessa: Instituto Plantarum, 2000. 352 p.

MACHADO, P. F.; LONGHI, S. J. Aspectos florísticos e fitossociológicos do "Morro do Elefante", Santa Maria, RS. Ciência Rural, Santa Maria, v. 20, n. 3-4, p. 261-280, 1990.

MACHADO, P. F.; LONGHI, S. J. Aspectos florísticos e fitossociológicos da floresta do morro Osório, RS, Brasil. Ciência e Natura, Santa Maria, n. 13, p. 103-115, 1991.

MACIEL FILHO, C. L. Carta geotécnica de Santa Maria. Santa Maria: UFSM - Imprenssa Universitária, 1990. 21 p.

MALUF, J. R. T. Nova classificação climática do estado do Rio Grande do Sul. Revista Brasileira de Agrometeorologia, Sete Lagoas, v. 8, p. 141$150,2000$.

MCCUNE, B.; MEFFORD, M. J. PC-ORD version 
5.0. multivariate analysis of ecological data. Glaneden Beach: MjM Solfware Desing, 2006.

MUELLER-DOMBOIS, D.; ELLENBERG, $\mathrm{H}$. Aims and Methods of Vegetation Ecology. New York: John Wiley e Sons, 1974. p. 67-134.

PEDRON, F. de A. et al. Utilização do sistema de avaliação do potencial de uso urbano das terras no diagnóstico ambiental do município de Santa Maria - RS. Ciência Rural, Santa Maria, v. 36, n. 2, p. 468-477, 2006.

PUIG, H. A floresta tropical úmida. São Paulo: Editora UNESP: Imprensa Oficial de São Paulo; França: Institut de Rechérche pour le Développement, 2008. 496 p.

RIBEIRO, S. B. et al. Diversidade e Classificação da comunidade arbórea da Floresta Ombrófila Mista da FLONA de São Francisco de Paula, RS. Ciência Florestal, Santa Maria, v. 17, n. 2, p. 101108, abr-jun, 2007.

SANTANDER, C. B.; GONZÁLEZ, I. A. G. Flora arbórea del Uruguay: con énfasis en las espécies de Rivera y Tacuarembó. Montevideo: Empresa Gráfica Mosca, 2007. 543 p.

SANTOS, R. D. et al. Manual de descrição e coleta de solo no campo. 5. ed. Viçosa: SBCS,
2005. 100p.

SCIPIONI, M. C. Distribuição do compartimento arbóreo em gradiente de relevo e solos na encosta Meridional da Serra Geral, RS. Ciência Rural, Santa Maria, v. 40, n. 6, p. 1295-1301, jun, 2010.

SCIPIONI,M.C.etal.Análise dospadrõesflorísticos e estruturais da comunidade arbóreo-arbustiva em gradientes de solo e relevo. In: SCHUMACHER et al. (Orgs.). Floresta Estacional Subtropical: Caracterização e Ecologia nas Escarpas da Serra Geral. Santa Maria: UFSM, 2011a. cap. 5, p. 3351.

SCIPIONI, M. C. et al. Fitossociologia em fragmento florestal no noroeste do estado do Rio Grande do Sul. Ciência Florestal, Santa Maria, v. 21, n. 3, jul-set, 2011 b.

VACARO, S. et al. Aspecto da composição florística e a categorias sucessionais do estrato arbóreo de três subseres de uma Floresta Estacional Decidual, no município de Santa Tereza, RS. Ciência Florestal, Santa Maria, v. 9, n. 1, p. 1-18, 1999.

VELOSO, $\mathrm{H}$. P. et al. Classificação da vegetação brasileira, adaptada a um sistema universal. Rio de Janeiro: IBGE, Departamento de Recursos Naturais e Estudos Ambientais, 1991.124 p. 